\title{
Evaluación del Comportamiento en Compresión de Morteros Reforzados con Óxido de Grafeno y Costos Inherentes al Proceso Productivo de Mezcla
}

\section{Compression Behavior of Mortar Reinforced with Graphene Oxide and Costs Inherent to the Production Process of the Mixture}

INFORMACIÓN DEL ARTÍCULO

Fecha de recepción: 10 de diciembre de 2018

Fecha de aceptación: 5 de febrero de 2019.
1 Universidad de Especialidades Espíritu Santo, Facultad de Arquitectura e Ingeniería Civil, Km. 2.5 Vía la Puntilla, Samborondón, Ecuador.

Escuela Superior Politécnica del Litoral, Facultad de Ingeniería, Ciencias de la Tierra, ESPOL, Km. 30.5 Vía Perimetral, Guayaquil, Ecuador.

Autor de correspondencia: Roa Olga Universidad de Especialidades Espíritu Santo, Facultad de Arquitectura e Ingeniería Civil, Km. 2.5 Vía la Puntilla, Samborondón, Ecuador.

E-mail: olgaroa@uees.edu.ec

Telf: (593-4) 283-5630 ext. 514

ENLACE DOI

http://dx.doi.org/10.31095/investigatio. 2019.12.3
Jhonnatan Ávila ${ }^{1}$, Hugo Eguez ${ }^{2}$, Olga Roa ${ }^{1 *}$

\section{Resumen}

Se propone evaluar la obtención de óxido de grafeno a partir de esquistos grafíticos procedentes del cerro Villonaco en la provincia de Loja-Ecuador, y de grafito sintético comercializado en Ecuador para reforzar químicamente morteros de cemento. Comparativamente se estudian mezclas de mortero reforzadas con óxido de grafeno reducido. El grafito natural es producto de la recristalización metamórfica de materia orgánica contenida en las rocas, cuando este proceso se produce sobre capas de carbón o sobre rocas que contienen hidrocarburos líquidos generando yacimientos. Las muestras de esquistos grafíticos son procesadas mecánica y químicamente separando las partículas de carbono de otros minerales o impurezas inorgánicas (sílice, alúmina, óxido férrico, otros) determinando el porcentaje de impurezas mediante un proceso de calcinación. Se ensayan 26 probetas cúbicas de mortero reforzadas con incrementos equidistantes entre $0,03-0,06 \%$ del peso de cemento en el mortero (ASTM-C-109), obteniendo una tendencia incremental de la resistencia mecánica a compresión.

\section{Palabras Clave:}

Compresión en morteros; óxido de grafeno; sintesis química de grafito. Clasificación JEL: C93.

\begin{abstract}
It is proposed to evaluate the obtaining of graphene oxide from graphitic shales from the Villonaco hill in the province of Loja-Ecuador, and from synthetic graphite marketed in Ecuador to chemically reinforce cement mortars. Comparatively mortar mixtures reinforced with reduced graphene oxide are studied. Natural graphite is the product of metamorphic recrystallization of organic matter contained in rocks when this process occurs on layers of coal or on rocks containing liquid hydrocarbons generating deposits. The graphitic shale samples are mechanically and chemically processed by separating the carbon particles from other minerals or from inorganic impurities (silica, alumina, ferric oxide, others) determining the percentage of impurities by means of a calcination process. Twenty-six cubic mortar test pieces reinforced with equidistant increments between 0.03-0.06\% of the weight of cement in the mortar (ASTM-C-109) are tested, obtaining an incremental tendency of the mechanical resistance to compression.
\end{abstract}

\section{Keywords:}

Chemical synthesis graphite; compressive strength mortars; graphene oxid. JEL Classification: C93.

49

INVESTIGATIO No. 12, marzo 2019, pp. 49-66,

ISSN: 1390 - 6399・ISSN-e: 2602 - 8336 


\section{Introducción}

La necesidad de mejorar las propiedades mecánicas de los morteros con bajos incrementos en los costos y utilizando procesos tecnológicos simples, puede lograrse implementando nuevos aditivos a las mezclas (Abrishami y Zahabi, 2016). Investigaciones sobre materiales compuestos combinados mecánicamente mediante una interface de unión posibilita lograr propiedades mejoradas en la composición, como es el caso de incorporar materiales de carbono en diferentes estructuras y escalas: fibras de carbono, los nanotubos de carbono, el grafeno y óxido de grafeno los cuales presentan propiedades mecánicas bien diferenciadas. La dispersión de dichas estructuras de carbono en mezclas de cemento, incide en que las características correspondientes a cada estructura de carbono se adicionen o no, adecuadamente a las mezclas de cemento (Goicoechea, 2017).

El grafeno, es una de las formas alotrópicas del carbono (Geim y Novoselov, 2007). El uso del término grafeno debe ser diferenciado según las características químicas del material, ya que sus propiedades y en consecuencia sus usos varían. Dichas denominaciones son: Grafito (G), Óxido de grafito (GO), Óxido de grafeno (G-O, mono capa de óxido de grafito, usualmente obtenida por exfoliación del óxido de grafito), Oxido de grafeno reducido (rG-O, material obtenido por reducción térmica o química del óxido de grafito o del óxido de grafeno eliminado gran parte del oxígeno (Ramos, 2017), otro método es la fototérmica, inducido por láser y reducción química
(Vargas,2016); este estudio trabajará con mortero reforzado con G-O y rG-O.

El proceso inicia con la obtención del grafito a partir de esquistos grafíticos, y debido a que existen distintos métodos para producir $\mathrm{G}-\mathrm{O}$, es importante tener presente que el grafito obtenido en la primera etapa, los diferentes oxidantes, ácidos y condiciones de reacción que se utilicen en el proceso influyen de manera importante en la estructura y tamaño del G-O resultante. Adicionalmente, para obtener óxido de grafeno (Graphene Oxide, G-O) se requiere aplicar un proceso de oxidación química al grafito, utilizando disolventes y/o surfactantes orgánicos. El grafito es un mineral suave y a la vez una forma alotrópica del carbono, de estructura cristalina hexagonal además es químicamente inerte a temperatura normal (Coordinación general de minería de México, 2014). El color del grafito es de gris a negro, presenta un brillo metaloide. El peso específico del grafito es de 2,3 $\mathrm{g} / \mathrm{cm}^{3}$ y su dureza está entre $1-2$ es inodoro, no tóxico, presenta resistencia al calor y es excelente conductor de calor y electricidad. El grafito por lo general está en contacto con otros minerales como: cuarzo, feldespato, micas, calcita, pirita y óxidos de hierro (Coordinación general de minería de México, 2014).

La presencia de oxígeno en el G-O, ocasiona que láminas de óxido de grafeno sean dispersables en agua (hidrofílicas), produciendo mayor superficie para la nucleación del gel de silicato de calcio C-S-H del cemento, otorgando propiedades mecánicas a la mezcla de cemento con de óxido de grafeno. 
El G-O posee las siguientes propiedades: módulo de elasticidad de 23 - 42 GPa., resistencia a la tracción 130 $\mathrm{MPa}$, rotura de alargamiento $0,6 \%$, densidad $1800 \mathrm{~kg} / \mathrm{m}^{3}$, espesor $0,67 \mathrm{~mm}$, área de superficie $700-1500 \mathrm{~m}^{2} / \mathrm{g}$ (Chuah et al., 2014); sin embargo, en la segunda década del siglo XXI la estructura atómica del óxido de grafeno no ha sido claramente definida debido a la composición no estequiométrica y a sus caracteres amorfos con distribución no homogénea de los grupos funcionales de oxígeno (Romani, 2015).

Son pioneros en el estudio del G-O: Brodie-1859, químico británico que sintetiza el óxido de grafeno por primera vez, luego de casi 40 años Staudenmaier-1898 modifica y mejora la síntesis (como se cita en Amor, 2017) generando un nuevo proceso para la oxidación del grafito con la incorporación de una mezcla de nitrato de sodio $\left(\mathrm{NaNO}_{3}\right)$ y permanganato de potasio $\left(\mathrm{KM}_{\mathrm{n}} \mathrm{O}_{4}\right)$ en una concentración de ácido sulfúrico concentrado $\left(\mathrm{H}_{2} \mathrm{SO}_{4}\right)$; otros autores han presentado nuevos procesos de oxidación, pero consiste fundamentalmente en el mejoramiento del método de Hummer. Marcano (2010) desarrolló un procedimiento que expulsa el nitrato de sodio (NaNO3) (con una toxicidad inferior del gas) resultando un material denominado óxido de grafeno mejorado, que presenta un nivel de oxidación más elevado y es estructuralmente más regular, además se obtiene una fracción superior de material hidrófilo bien oxidado (Romani, 2015). El G-O es uno de los materiales más investigados a nivel mundial en búsqueda de técnicas más eficientes de síntesis químicas, además de económicas y seguras; se ha incorporado en el estudio de materiales de construcción; por ejemplo, en el refuerzo de hormigones y morteros para mejorar su desempeño resistivo ante cargas.

En general un mortero reforzado contribuye en el mejor desempeño de las estructuras respecto a la vulnerabilidad sísmica, actuando como elemento de unión resistente y comparte las solicitaciones del sistema constructivo en el que esté integrado (Rodríguez, 2008). El desarrollo de técnicas de reforzamiento químico de mortero con G-O evidencia que las propiedades de la mezcla varían dependiendo de su procedencia, proceso productivo, su síntesis química, entre otros. Por ello se planteó responder: ¿En qué porcentaje se incrementa la resistencia mecánica a compresión de morteros cuando es reforzado con óxido de grafeno obtenido mediante la técnica "Improved Synthesis of Graphene Oxide", y cuál es el costo estimado para obtener una unidad de volumen de muestra para ensayo?

Las propiedades que presenta el mortero en estado fresco son: adherencia, docilidad, tixotropía, rendimiento, retención de agua, cohesividad, tiempo abierto, ausencia de segregación y exudación. Las propiedades del mortero en estado endurecido son: resistencia a la compresión, resistencia a flexotracción, impermeabilidad, textura superficial, resistencia a las heladas, ausencia de fisuras, ausencia de eflorescencias, durabilidad (Dominguez y Adrados, 
1997). En este estudio la resistencia a compresión es la propiedad más relevante.

La resistencia a la compresión del mortero depende fundamentalmente de la cantidad de cemento y de la relación en peso del agua libre (w) y el peso del cemento (c) (Instituto Ecuatoriano de Normalización, 2010). De total del agua que participa en la elaboración del mortero, una parte se absorbe al interior de los áridos y la cantidad restante de agua se denomina agua libre. Solo una cierta cantidad del agua libre tiende a reaccionar con el cemento y la restante que no interviene en la reacción forma parte del amasado, y luego tiende a evaporarse por tanto deja en su lugar poros de aire (Kehr, 2008). La resistencia del mortero será menor a mayor cantidad de agua que no logra combinarse, sin embargo, cuando se utiliza relaciones agua/cemento demasiado bajas la mezcla tiende a ser más seca y difícil de compactar generando porosidad, al punto que la resistencia comenzará a disminuir (Kehr, 2008).

En este trabajo se plantea la obtención de óxido de grafeno a partir de grafito "la estructura del grafito puede considerarse una pila de gran cantidad de láminas de grafeno superpuestas" (Totarolo y Prisant, 2012) por medio de la técnica de síntesis química "Improved Synthesis of Graphene Oxide" (Marcano et al., 2010). Dicha técnica de síntesis química se seleccionó basados en los siguientes criterios: los equipos de laboratorio disponibles en Guayaquil para realizar el trabajo práctico, la posibilidad de obtener una mayor producción de óxido de grafeno, la mejor adherencia al cemento debido a una mayor hidrofilia, la menor emisión de gases tóxicos durante el proceso de síntesis. Por otra parte, con la evaluación de grafito procedente de Ecuador y el análisis de los costos del proceso productivo se busca establecer una base en la toma de decisiones sobre el uso de este material en pro del desarrollo tecnológico. La producción a gran escala con una relación de bajo costo y alta calidad es uno de los retos en la comercialización del grafeno.

\section{Materiales y Métodos}

Basados en el trabajo de Uribe (2015) que identifica el número de ocurrencias de minerales no metálicos en 19 provincias del Ecuador, solo en las provincias de Loja y Zamora se señala la presencia de grafito. A partir de la revisión bibliográfica de los yacimientos de grafito, el yacimiento del cerro Villonaco de la provincia de Loja, cuenta con estudios previos de cartografía y análisis petrográfico (González, 2016) motivo por el cual se selecciona como zona de estudio para la extracción de esquistos grafitícos como materia para obtener grafito.

La selección de puntos de prospección para la recolección de las muestras en el yacimiento, se realizó por medio de la exploración del subsuelo basada en el examen de los caracteres del terreno (Figura 1: 1.c - 1.f). Existen tres procedimientos de extracción de muestras: extracciones puntuales (al azar, por puntos o en sondeos), extracciones lineales (en calicatas y sondeos) y 
extracciones volumétricas (procedimientos a rastrillo y global). En este estudio se selecciona el procedimiento de extracciones puntuales aleatorias sobre las vetas dentro de un estrato. Las muestras se toman al desprender trozos de roca de aproximadamente de $0,5 \mathrm{Kg}$ a $2 \mathrm{~kg}$, de ocho diferentes puntos en el cerro Villonaco, las dimensiones de las muestras oscilan en un rango de $10 \times 5 \mathrm{~cm}^{2}$ a 19x24 $\mathrm{cm}^{2}$ aproximadamente con espesor variable entre 3 y $10 \mathrm{~cm}$. El peso total de las muestras fue de $36 \mathrm{~kg}$.

Debido a que en el estudio se debe considerar lo siguiente para la preparación y ensayo de probetas: obtención de grafito, síntesis química, dosificación de mortero, tipo de cemento - áridos y aditivos, método de incorporación de óxido de grafeno en mortero, porcentaje de óxido de grafeno en el mortero, tiempos de fraguado, a continuación, se desciben los procedimientos empleados.

\section{Procedimiento de molienda y tamizado}

El procedimiento se realizó el laboratorio de Mineralurgia de la Facultad de Ingeniería de Ciencias de la Tierra (FICT) de la ESPOL. Las muestras de esquistos grafitícos son sometidas a tres etapas de molienda para posteriormente iniciar con el procedimiento de flotación de minerales. Se realiza la fractura de los esquistos de grafito de gran tamaño en la trituradora de mandíbulas totalizando ocho bandejas de $50 \times 25 \times 15 \mathrm{~cm}^{3}$ con un tamaño de grano de aproximadamente $50-100 \mathrm{~mm}$. Posteriormente, en la segunda etapa para conseguir un tamaño de grano aproximado de $20-40 \mathrm{~mm}$, se utilizó la trituradora de rodillos. En la tercera etapa, para obtener un tamaño de grano aproximado de $2 \mathrm{~mm}-100 \mu \mathrm{m}$ se introduce el material en el molino de discos. Finalmente esté material tamizado

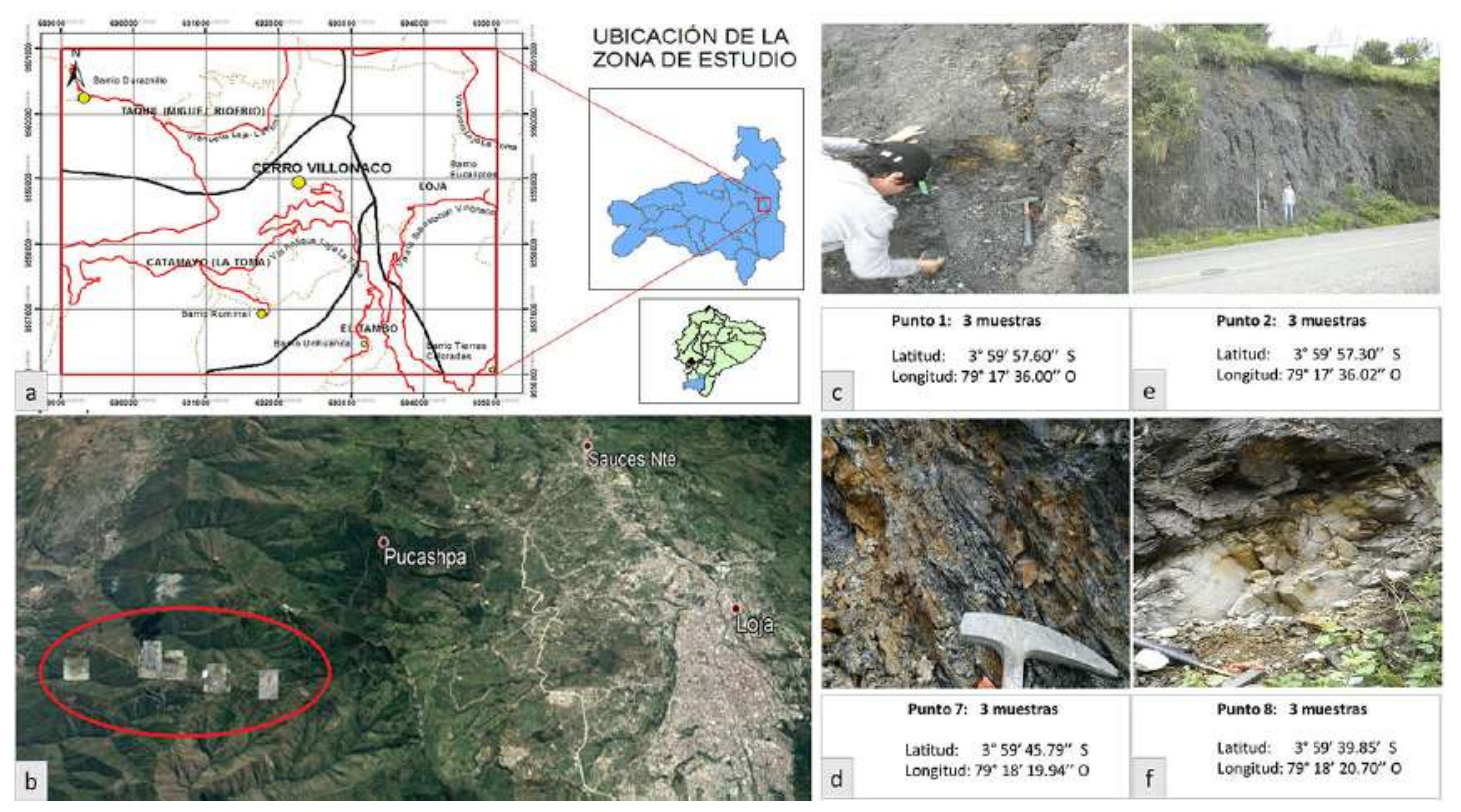

Figura 1. a.- Ubicación de zona de estudio (Burneo, 2015); b.- Vista satelital de la zona de estudio; c-f.- Puntos de toma de muestras de esquistos (adaptado de Google Earth). 
por los tamices de 50 y 100 (Figura 2).

\section{Procedimiento de flotación de minerales}

La flotación de minerales es un procedimiento que consiste en la separación selectiva de partículas en función de su hidrofobicidad. En el proceso es necesario utilizar reactivos como los espumantes, que tienen por función generar burbujas de tamaño pequeño y una fase de espuma estable (Orozco, 2012). Dichas espumas tenso-activas o surfactantes están conformadas por una parte polar (hidrofílica) y una parte apolar (hidrofóbica). En la superficie de la burbuja (interface aire-agua), la cadena hidrocarbonada se orienta hacia el lado del aire y el grupo polar hacia el lado del agua (Orozco, 2012).

Producto del proceso de flotación se obtuvo pulpa constituida por una mezcla de agua + grafito. Agitando la pulpa durante $3 \mathrm{~min}$ a 1500 r.p.m., este se disuelvió en el agua y se obtivo una pulpa
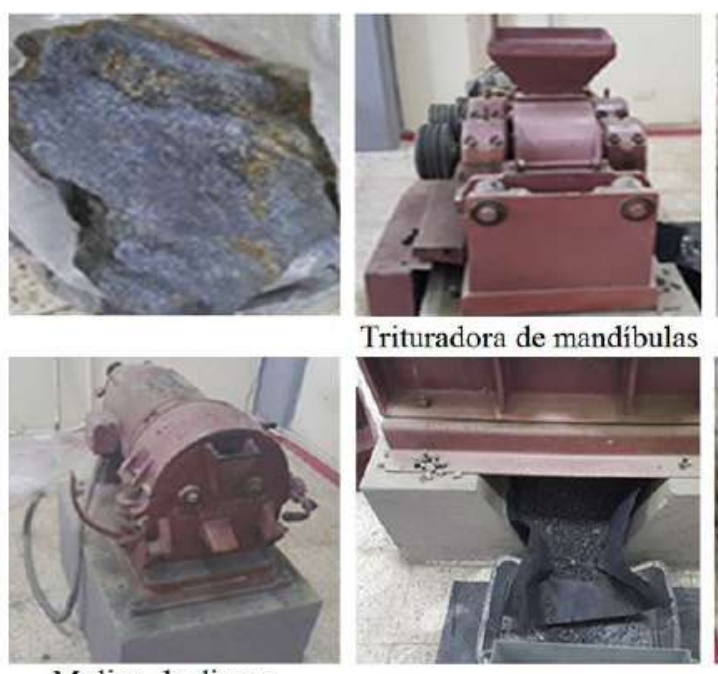

uniforme. La pulpa obtenida posee una densidad del 7\% (relación determinada por $0,07=S /(S+L))$. Posteriormente, se agregó $5 \mathrm{ml}$ de queroseno a la pulpa y se agitó durante 2 min a 1500 revoluciones por minuto (r.p.m.) con la finalidad de que el queroseno actúe como flotador haciendo que otros minerales diferentes al carbono se depositen al fondo del recipiente metálico.

Se agregaron 5 gotas de espumante 370 y se aumentaron las revoluciones a 1800 r.p.m. durante 5 min (luego de ese tiempo se alcanzo un contenido de otros materiales diferentes al carbono), y para obtener espuma en la superficie la cual presenta un mayor contenido de carbono, la cantidad de espuma es experimental. Se procedió a retirar la espuma presente en la pulpa y a colocarla en dos bandejas para su posterior secado. Se llevó la bandeja con el material a un horno a $70^{\circ} \mathrm{C}$ durante $24 \mathrm{~h}$ aproximadamente, para lograr deshidratar la mezcla. Se obtuvo aproximadamente $3000 \mathrm{mg}$ de grafito. Los materiales y etapas del proceso se
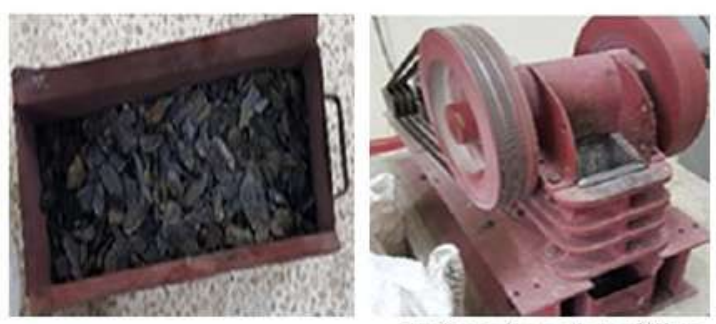

Trituradora de rodillos
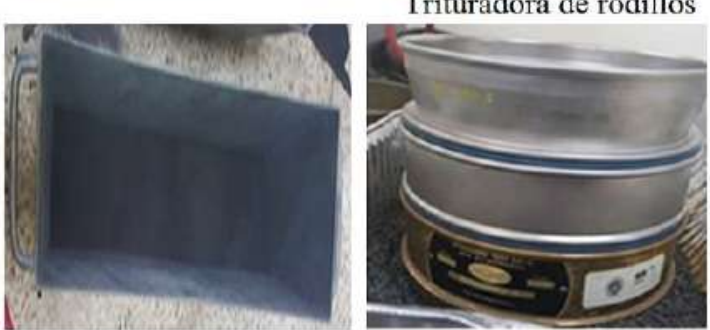

Figura 2. Materiales y equipos requeridos en el proceso de molienda y tamizado de esquistos de grafito.

54

INVESTIGATIO No. 12, marzo 2019, pp. 49-66,

ISSN: 1390 - 6399・ISSN-e: 2602 - 8336 


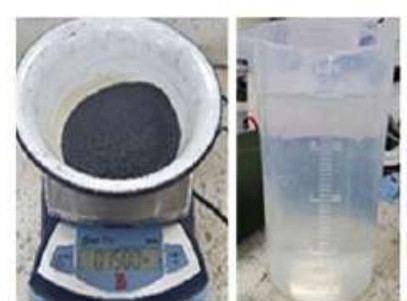

$0,15 \mathrm{Kg}$ de grafito 2 lt de agua

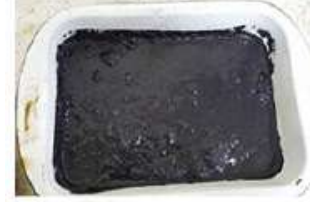

Bandeja con espuma

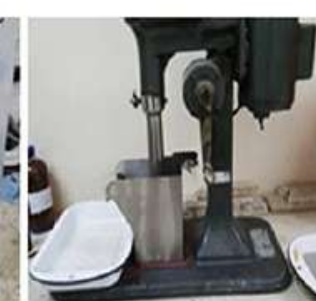

$5 \mathrm{ml}$ de keroseno

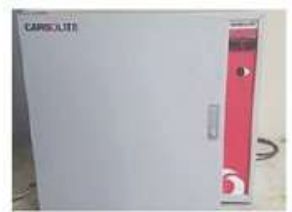

Secado en horno
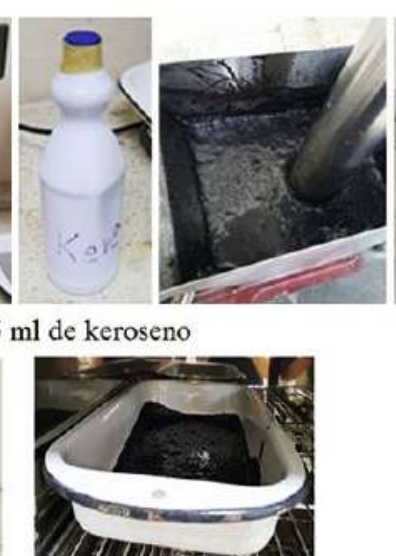

Figura 3. Materiales y equipos requeridos en el proceso de flotación de minerales
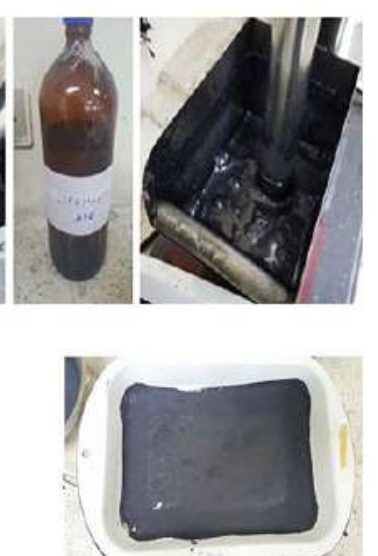

Espuma luego de $24 \mathrm{~h}$ presentan en la Figura 3.

Procedimiento de calcinación de grafito

El procedimiento de calcinación se realizó en el laboratorio de Hidrocarburos del Facultad de Ciencias Naturales y Matemáticas (FCNM de la ESPOL). El objetivo de este procedimiento fué determinar la cantidad de carbono presente en las muestras. Luego de los procesos de calibración del equipo se procede a pesar
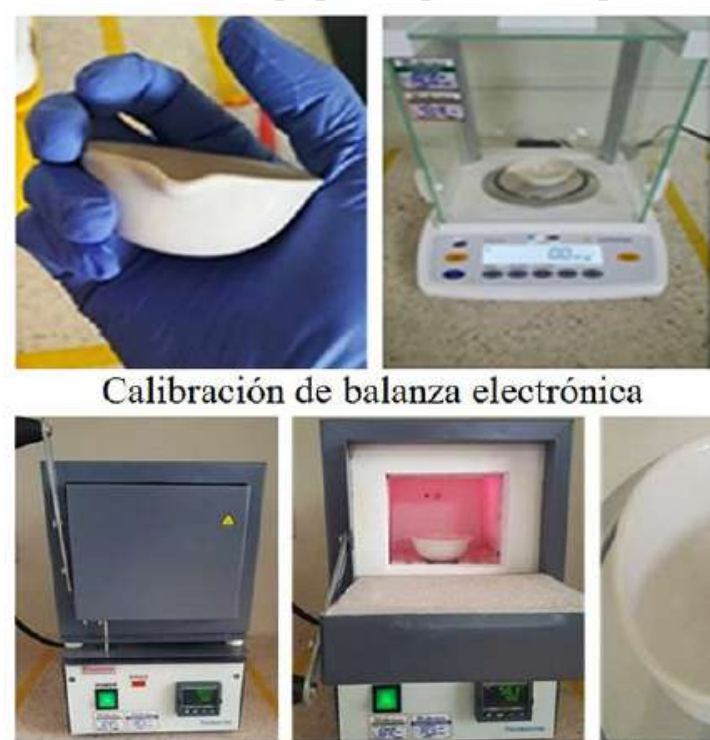

Calcinación en horno
$1000 \mathrm{mg}$ de grafito en el crisol de porcelana. Para la calcinación de la muestra de grafito se utilizó la mufla por 45 minutos a una temperatura de $700^{\circ} \mathrm{C}$, luego se pasó a un desecador y se repitió el pesaje de la muestra, por la diferencia de pesos se determinó la cantidad de carbono presente en la muestra, alcanzando un valor aproximado de $6,19 \%$ de carbono presente en 1000 miligramos de la muestra de grafito. Los materiales y etapas del proceso se representan en la Figura 4.

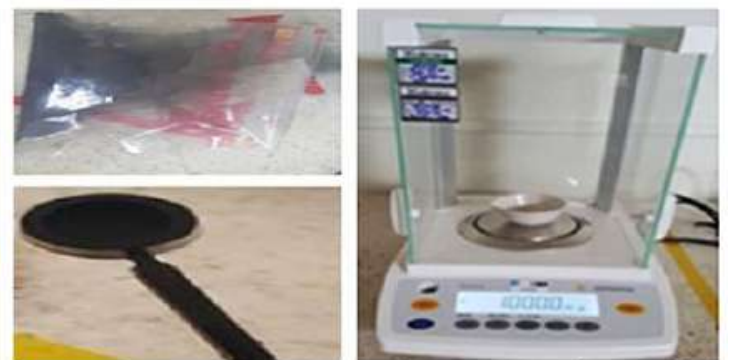

Pesaje muestra de grafito
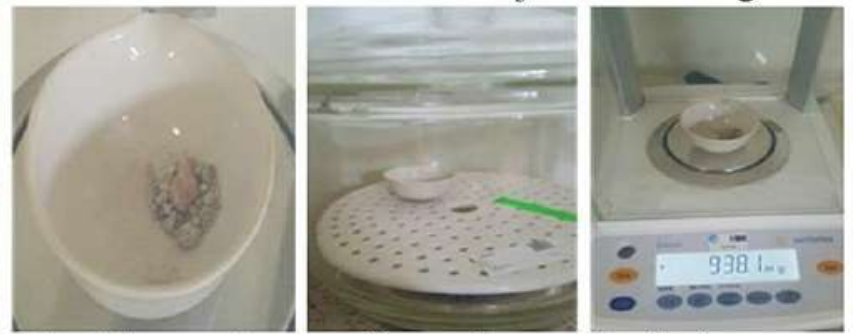

Desecado Pesaje de muestra

Figura 4. Materiales y equipos requeridos en las diferentes etapas del proceso de calcinación de grafito para determinar la cantidad de carbono presente. 


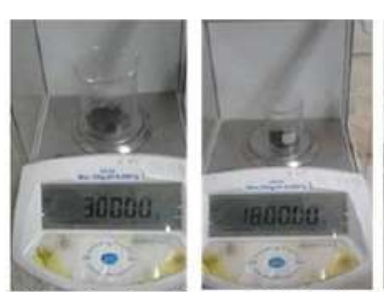

Pesaje Grafito y $\mathrm{KMnO}_{4}$

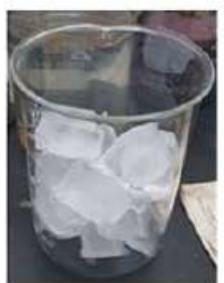

Mezcla thielo desionizado y $6 \mathrm{ml} \mathrm{de} \mathrm{H}_{2} \mathrm{O}_{2}$

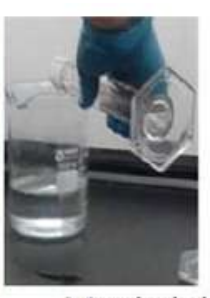

Mezcla de los àcidos $\mathrm{H}_{2} \mathrm{SO}_{4}, \mathrm{H}_{3} \mathrm{PO}_{4}$
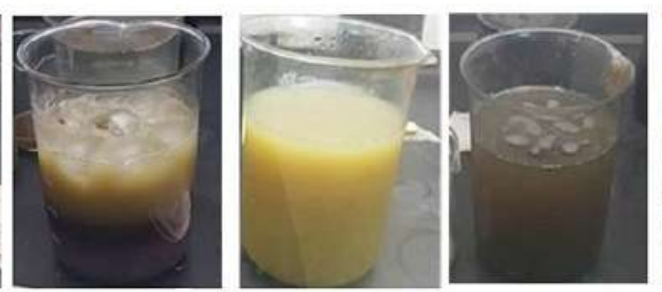

Cambio de colores en mezcla
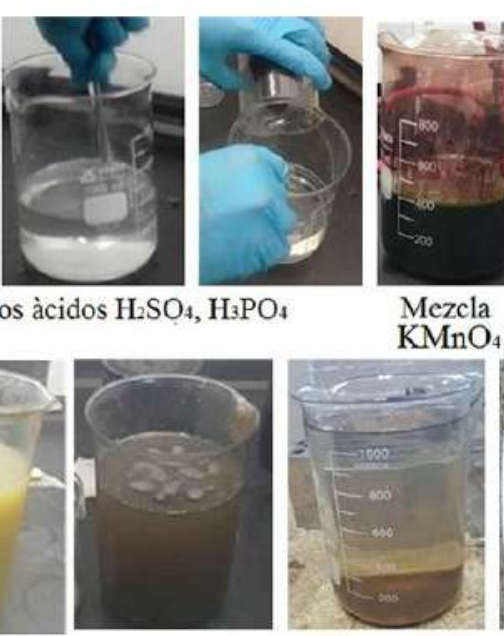

Sedimentación

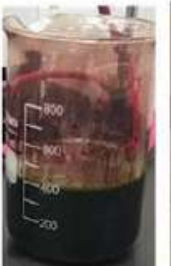

Mezcla

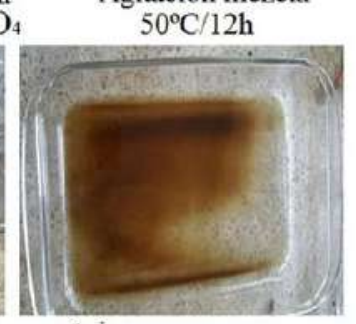

Òxido de Grafeno

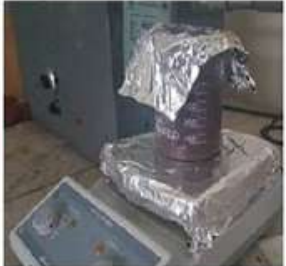

Agitación mezcla

a

Figura 5. Materiales y equipos requeridos en las diferentes etapas de síntesis química para obtener G-O.

\section{Procedimiento de síntesis química}

La técnica de síntesis química "Improved Synthesis of Graphene Oxide", requiere de los siguientes compuestos químicos: ácido sulfúrico, ácido clorhídrico y permanganato de potasio; dado que el grafito procedente del cerro Villonaco es altamente contaminado. Se decidió utilizar grafito sintético comercializado en Ecuador (Ecuacarbones), y según la disponibilidad de los compuestos químicos se logró realizar tres procesos de síntesis, en cada uno se utilizaron $3 \mathrm{~g}$ de grafito sintético. Se evaluaron los costos derivados del proceso de síntesis para obtener óxido de grafeno mediante el método de síntesis Improved Synthesis of Graphene Oxide.

El procedimiento de síntesis inició pesando $3 \mathrm{~g}$ de grafito y $18 \mathrm{~g}$ de permanganato de potasio, se usan $360 \mathrm{ml}$ de ácido sulfúrico al $96 \%$ y $40 \mathrm{ml}$ de ácido fosfórico al $75 \%$. Se mezclan el ácido sulfúrico con el ácido fosfórico produciendose una reacción exotérmica de aproximadamente $35^{\circ} \mathrm{C}$. Se procedió a mezclar el grafito con los ácidos y agregar muy lentamente pequeñas cantidades de permanganato de potasio, evitando que se produzcan una explosión que arruinaría la síntesis. En un agitador con calentador se colocó la mezcla a una temperatura de $50{ }^{\circ} \mathrm{C}$ durante 12 horas. Luego de las 12 horas se colocaron 400 $\mathrm{ml}$ de hielo desionizado en un vaso precipitado y se agregó $6 \mathrm{ml}$ de peróxido de hidrógeno al 3,5\%, obteniendo un color amarillo brillante que cambiara a oscuro. Al decantar, se limpió la mezcla para obtener óxido de grafeno. Se agregó en un vaso precipitado $75 \mathrm{ml}$ de la mezcla con $1000 \mathrm{ml}$ de agua. El objetivo de este paso fue disminuir la cantidad de ácidos en la mezcla. Posteriormente, se vació en cinco bandejas de vidrio la mezcla con el objetivo de secar la muestra, se obtienen aproximadamente $6 \mathrm{~g}$ de G-O, (Figura 5).

Se colocó el óxido de grafeno en papel filtro sobre un embudo conectado a su vez 

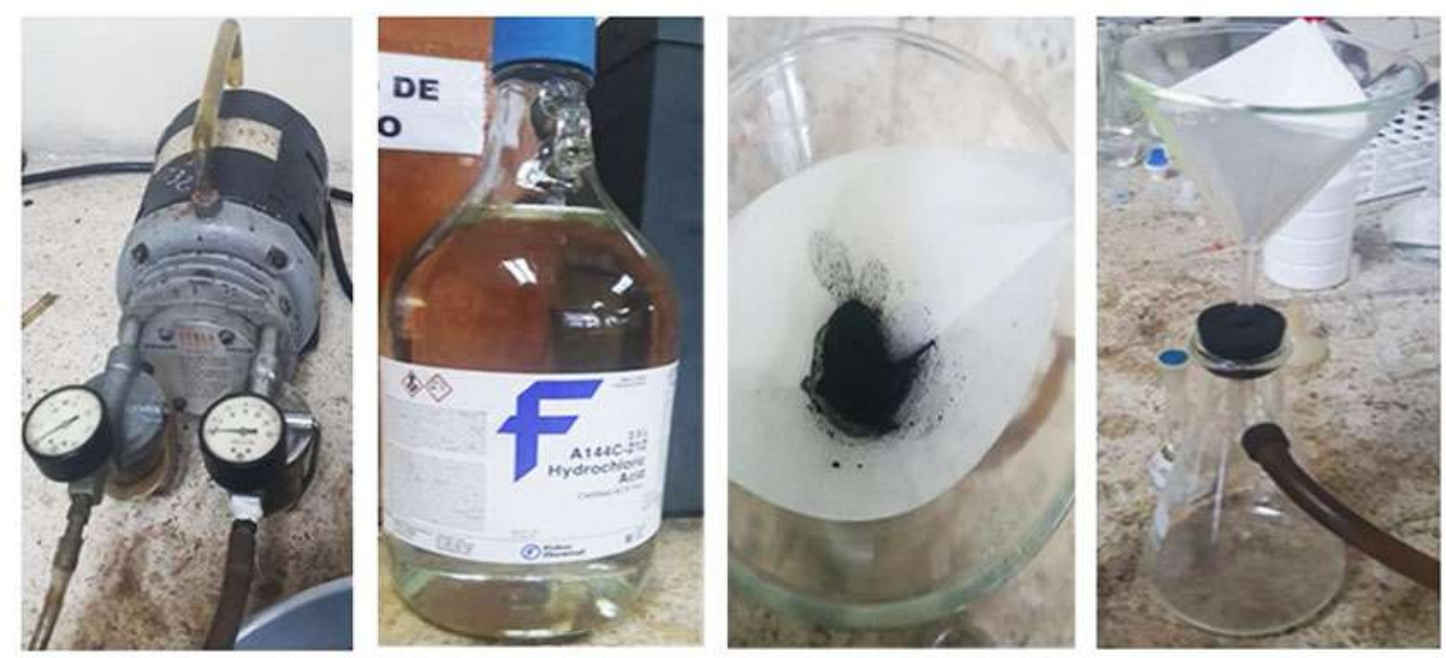

Figura 6. Materiales y equipos requeridos para la purificación de la muestra de G-O.

a una bomba de vacío a continuación se añadió $3 \mathrm{ml}$ de ácido clorhídrico (Figura 6). El objetivo fue purificar la muestra de óxido de grafeno.

Se obtuvo $6 \mathrm{~g}$ de óxido de grafeno (de textura acuosa) el cual debía ser centrifugado y filtrado a $0.45 \mu \mathrm{m}$, para lo cual se utilizó un proceso alternativo de secado en bandeja propuesto por el investigador Robert Murray Smith (2013). Se prepararon cinco bandejas contentivas de aproximadamente $1,2 \mathrm{~g}$ de mezcla cada una y se logró obtener $0,66 \mathrm{~g}$ de óxido de grafeno (de una sola de las bandejas), los cuales fueron utilizados en el diseño de 12 probetas de mortero (Murray, 2013). Por otra parte, con el interés de validar el comportamiento mecánico del óxido de grafeno sintetizado, se prepararon 11 nuevas probetas de mortero con 400mg rG-O (adquirido en los Estados Unidos). Es importante resaltar que el óxido de grafeno reducido (Reduced Grapehene Oxide, rG-O) es un análogo al grafeno debido a que en él se han eliminado de forma parcial o completa los grupos oxigenados, lo que le confiere propiedades mecánicas similares.

Procedimiento de preparación de la mezcla y construcción de probetas de mortero para ensayo de compresión

El mortero a ser reforzado con G-O está constituido por cemento, grava, arena y agua. El cemento Portland tipo I, los áridos (provienen de la disgregación de las rocas) tienen la función de reducir la retracción en el mortero ayudando adicionalmente a la carbonatación, incrementando la porosidad de conglomerantes para que el anhídrido carbónico presente en el aire pueda ingresar fácilmente en la masa y estabilizar su volumen (Trujillo, 2011). El agua presente en la mezcla es la agregada al desarrollar la pasta de mortero más el agua presente por la humedad superficial de los agregados, permitiendo la reacción química en el cemento y la hidratación para manipular la mezcla fresca (Carrasco, 2013). Finalmente, los 
Tabla 1

Clasificación de los morteros de pega para mampostería simple según resistencia a la compresión y según dosificación (adaptado de ASTM International, 2004).

\begin{tabular}{|c|c|c|c|c|}
\hline $\begin{array}{l}\text { Tipo de } \\
\text { Mortero }\end{array}$ & $\begin{array}{l}\text { Resistencia a la } \\
\text { compresión mínima } \\
\text { (MPa) } 3 \text { días }\end{array}$ & $\begin{array}{l}\text { Resistencia a la } \\
\text { compresión mínima } \\
\text { (MPa) } 7 \text { días }\end{array}$ & $\begin{array}{l}\text { Resistencia a la compresión } \\
\text { mínima MPa) } 14 \text { días }\end{array}$ & $\begin{array}{l}\text { Resistencia a la compresión } \\
\text { mínima (MPa) } 28 \text { días }\end{array}$ \\
\hline M & 6,88 & 11,18 & 15,48 & 17,2 \\
\hline $\mathrm{S}$ & 4,96 & 8,06 & 11,16 & 12,4 \\
\hline $\mathrm{N}$ & 2,08 & 3,38 & 4,68 & 5,2 \\
\hline $\mathrm{O}$ & 0,96 & 1,56 & 2,16 & 2,4 \\
\hline $\mathrm{K}$ & 0,20 & 0,325 & 0,45 & 0,5 \\
\hline
\end{tabular}

Se designaron las letras M, S, N, O y K, las cuales corresponden al deletreo de cada dos letras de la palabra "MaSoN wOrK o trabajo de mampostería" (Sanchéz, 2011).

aditivos o sustancias que al ser agregados al mortero modifican: sus propiedades originales, los requerimientos de fluidez, el tiempo de fraguado y la necesidad de modificar la resistencia mecánica (Alarcon, 1998).

Según la norma ASTM C109 las cantidades de materiales que se requieren para elaborar de seis a nueve especímenes son: Cemento 500g - 740g; Arena 1375g2035g; Agua 242ml - $359 \mathrm{ml}$. La preparación de probetas de mortero para ensayo utiliza el curado o proceso que evita las retracciones del mortero cuando fragua (períodos recomendados: 7, 14, 21 o 28 días) permitiendo así que el mortero alcance el nivel máximo de sus propiedades. Si el curado es incorrecto (niveles inadecuados de agua o tiempo de fraguado inferior al tiempo requerido en función del tipo de ensayo) la resistencia mecánica podría perder hasta un $30 \%$ del valor esperado (Fallas et al., 2011).

En la norma ASTM se identifican los distintos tipos de mortero asignando una letra (M, S, N, O y $\mathrm{K})$ según sus propiedades y aplicaciones (Gonzalez,
2016; Tabla 1).

Se procedió a medir los pesos de los diferentes porcentajes de óxido de grafeno con respecto al peso de cemento en un rango de $0,03 \%$ a $0,06 \%$ con incrementos de $0,01 \%$. Para cada porcentaje se prepararon 3 probetas reforzadas con óxido de grafeno procedente de la síntesis de grafito sintético, y 3 probetas reforzada con óxido de grafeno reducido. El ensayo de los cubos de mortero reforzados se realizaró mediante una carga puntual de compresión (ASTM International, 2008). El mortero trabajará como un elemento recto de sección constante sometido a un estado de fuerza que se localiza teóricamente en el centroide de la sección transversal perpendicular a dichas fuerza. Los esfuerzos normales $(S)$ en todo el elemento se representan mediante la siguiente ecuación:

$$
\left.S= \pm \frac{F}{A} \quad \text { (ec. } 1\right)
$$

Donde A representa el área de la sección transversal, y el signo dependerá de la dirección de la fuerza $(F)$. En la 


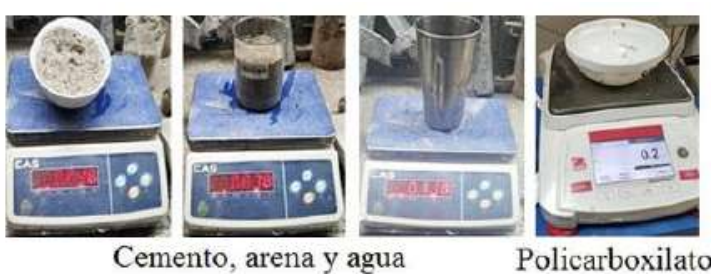

Cemento, arena y agua
Policarboxilato

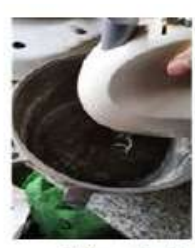

Mezcla 1: $\mathrm{GO}+\mathrm{H} 2 \mathrm{O}+$ Policarboxilato
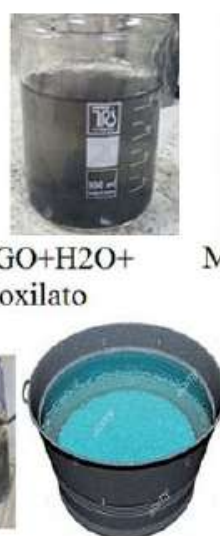

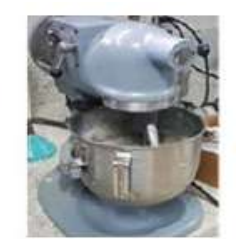

Mezcla 2: mortero + mezcla 1

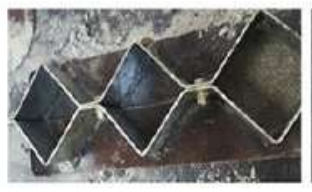

Moldes engrasados

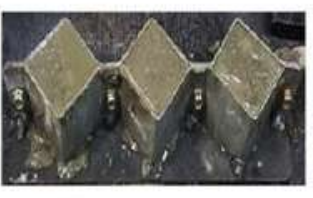

Moldes con mortero

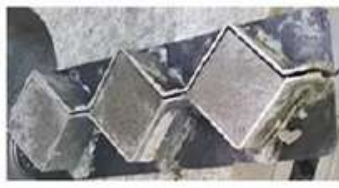

Desmontaje de moldes

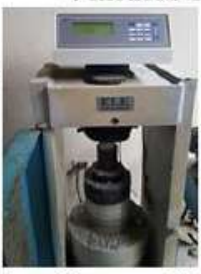

Maq. Compresión

Figura 7. Etapas de preparación de muestras cúbicas de mortero reforzado con G-O y rG-O para ensayo a compresión.

Figura 7 se representan las diferentes etapas realizadas en el proceso de construcción de las probetas para ensayo.

\section{Resultados y discusión}

Una vez realizados los procedimientos de laboratorio, se determina que el grafito presente contiene $90 \%$ de otros minerales (cuarzo, arcilla, óxido de hierro, entre otros) lo que lo define como grafito contaminado. En este sentido se recomienda realizar la toma de muestras de grafito utilizando otro método de extracción, por ejemplo, los métodos lineales (en calicatas y sondeos) o extracciones volumétricas, a fin de verificar si la pureza del grafito varía respecto al nivel superficial en el que se tomaron las muestras. En el procedimiento utilizado el contenido de grafito obtenido no logaría sintetizar la cantidad de óxido de grafeno suficiente para realizar un número representativo de probetas de mortero para ensayo $(<0,3 \mathrm{~g}$ de grafito).

Utilizando grafito sintético se procede a obtener óxido de grafeno realizando la síntesis "Improved Synthesis of Graphene
Oxide" debido a los beneficios que presenta respecto a otros tipos de síntesis: mayor cantidad de G-O, mayor cantidad de grupos funcionales oxigenados, menor presencia de gases tóxicos. Posteriormente, se procede al reforzamiento de morteros que son sometidos a cargas de compresión (Lv et al., 2013; Wang et al., 2015; Abrishami y Zahabi, 2016; Long et al., 2017).

Para comparar el comportamiento a compresión de cubos de mortero utilizando óxido de grafeno con el método de síntesis química "Improved Synthesis of Graphene Oxide" versus cubos de mortero con incorporación de óxido de grafeno reducido (rG-O) se realizó una recopilación de los datos publicados en 4 estudios de mezclas de morteros reforzadas con óxido de grafeno. En 2013 el trabajo se realizó a nivel micro estructural para determinar el efecto de la incorporación de nanoláminas de óxido de grafeno en mezclas de cemento y su incidencia en la resistencia mecánica a compresión. En el estudio los incrementos de resistencia mecánica a compresión más altos fueron alcanzados en el porcentaje de $0,05 \%$ de G-O (con respecto a peso de 
cemento), sus resultados son: 59,1\% y $47,9 \%$ de incremento para 3 y 28 días, respectivamente (Lv et al., 2013).

En 2015 se investigó la fluidez, viscosidad, tiempo de fraguado del mortero, morfología, estructura de poro, resistencia a la compresión y flexión como el calor de hidratación mediante SEM en morteros. En el artículo los incrementos de resistencia mecánica a compresión más altos se lograron en el porcentaje de $0,05 \%$ de G-O, las resistencias son: $43,2 \%, 33 \%$ y $24,4 \%$ de incremento para 3, 7, 28 días, respectivamente (Wang et al., 2015).

En 2016 se realizaron estudios de grupos funcionalizados con óxido de grafeno en morteros y su interacción con la microestructura del cemento, así como el incremento de resistencia mecánica a compresión de los morteros comparando sus resultados con mortero incorporado solo con óxido de grafeno. En el estudio los incrementos de resistencia mecánica a compresión más elevados fueron en el

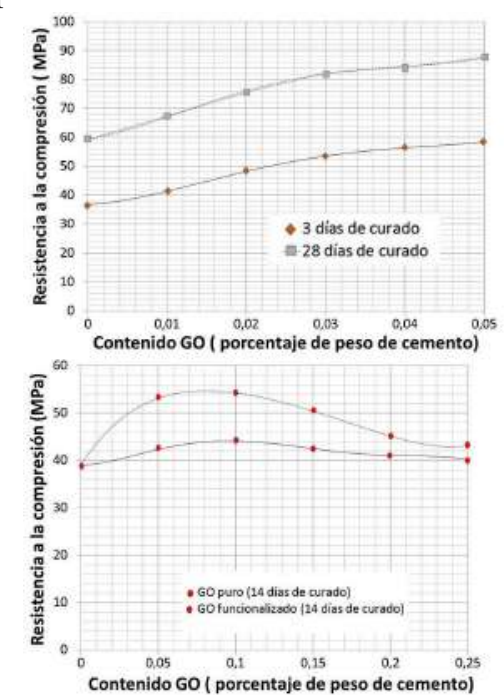

porcentaje $0.1 \%$ de G-O para 14 días. Los resultados obtenidos son: $13,0 \%$ y $39,1 \%$ para G-O puro y G-O funcionalizado (Abrishami y Zahabi, 2016).

En 2017 se presentó una investigación experimental sobre el efecto de las nanoláminas de óxido de grafeno (G-O) uniformemente dispersadas en compuestos a base de cemento preparados con agregado fino reciclado (RFA). Además, con ayuda de una microscopía electrónica de barrido se realizó un análisis micro estructural, que mostró que los compuestos de cemento G-O tenían una estructura mucho más densa y mejores productos de hidratación cristalizada, mientras que la prueba de porosimetría de intrusión de mercurio (MIP) y el análisis de imágenes demuestran el refinamiento en la estructura de los poros capilares y reducción del contenido de vacíos de aire. Los incrementos máximos de la resistencia a la compresión fueron $16,4 \%$ y $16,2 \%$ para el mortero RFA que contenía $0,2 \%$ de G-O a 14 y 28 días. Dichos resultados se presentan en la Figura 8.

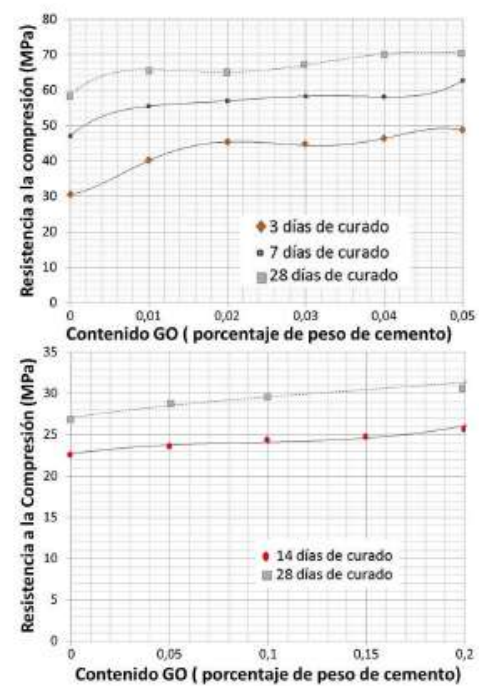

Figura 8. Curvas de contenido de óxido de grafeno en morteros versus resistencia a la compresión para morteros reforzados con óxido de grafeno, casos de estudio (a) (Lv et al., 2013). (b) (Wang et al., 2015). (c) (Abrishami y Zahabi, 2016). (d) (Long et al., 2017). 


\section{Tabla 2.}

Cantidades requerida de G-O y rG-O para reforzar probetas de $5 * 5 * 5 \mathrm{~cm} 3$, y resistencias mecánicas a la compresión de muestras de cúbicas de mortero con 14 días de curado reforzadas con G-O y rG-O respectivamente.

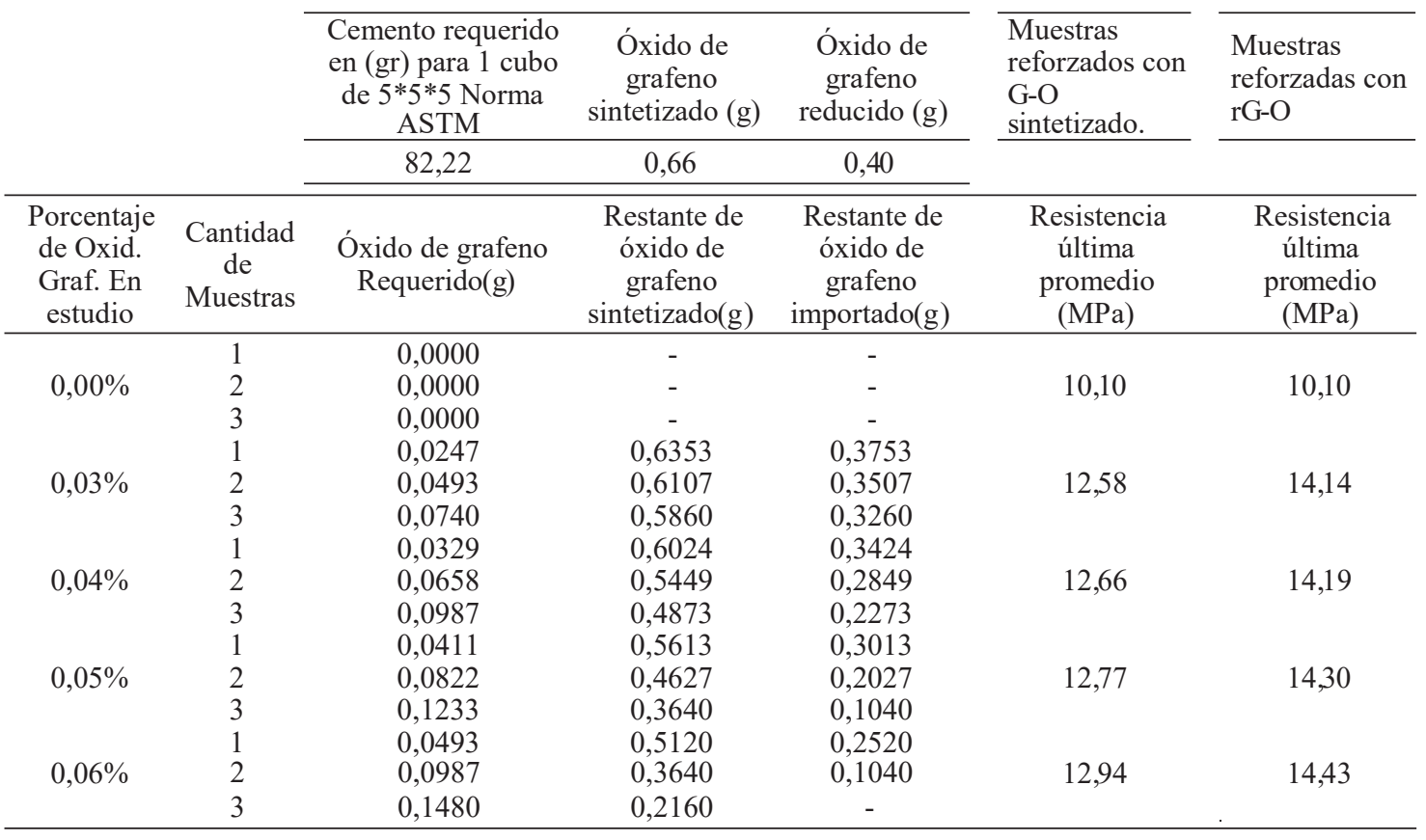

Para medir la resistencia mecánica a la compresión de diferentes relaciones de G-O $(0,3 ; 0,4 ; 0,5$ y $0,6 \%)$ presente en la mezcla de mortero con igual tiempo de fraguado, se utilizó la norma ASTM C109 para proceder a realizar las probetas cúbicas. Se construyen 12 muestras con óxido de grafeno procedente de grafito sintético y 11 muestras con óxido de grafeno reducido, además se utilizó policarboxilato en la mezcla para

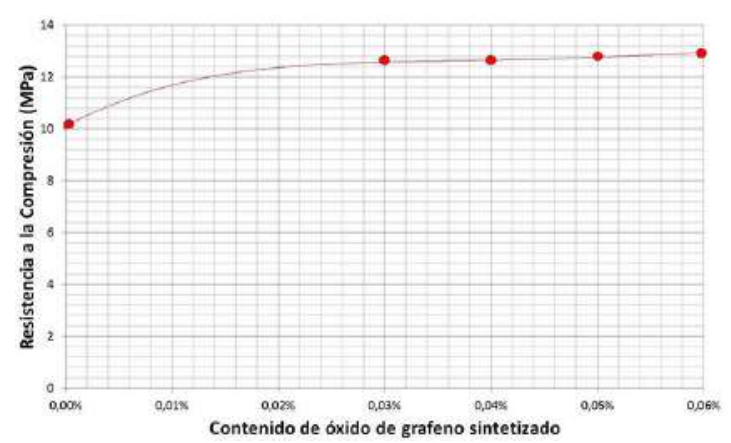

incrementar la adherencia del G-O en el mortero. Se utiliza un total de 26 moldes para cubos de mortero $(23+3$ muestras sin G-O). Luego de 14 días de curado, los cubos de mortero fueron sometidos a compresión. En la Tabla 5, se detallan las cantidades disponibles de óxido de grafeno sintetizado y reducido, y las cantidades requeridas de G-O por número de muestras. Se registran los datos de resistencia última del material, Tabla 2 y Figura 9.

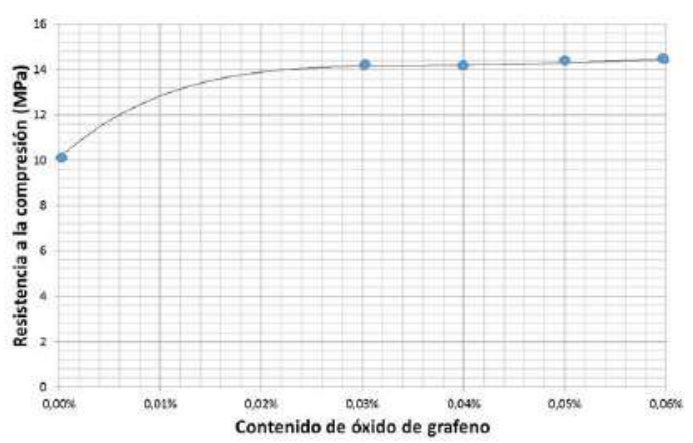

Figura 9. Resistencia a la compresión de cubos de mortero a 14 días con diferentes contenidos de óxido de grafeno: (izq.) sintetizado, (der.) reducido. 


\section{Análisis de costos}

Para evaluar los costos implicados en la producción de óxido de grafeno, se incluye en como base los costos de transporte, mano de obra, maquinaria o equipos (nacionales), honorarios profesionales, administración los cuales ascienden a un monto de 9578 US\$, este monto puede varíar en $\pm 20 \%$ en función de los equipos

\section{Tabla 3 .}

Costos de materiales para síntesis de óxido de grafeno.

\begin{tabular}{lcccccc}
\hline $\begin{array}{c}\text { Materiales requeridos } \\
\text { para realizar la síntesis } \\
\text { química }\end{array}$ & $\begin{array}{c}\text { Cantidad } \\
\text { adquirida } \\
\text { (CA) }\end{array}$ & $\begin{array}{c}\text { Costo } \\
\text { CA (\$) }\end{array}$ & $\begin{array}{c}\text { Cantidad } \\
\text { consumida (CC) }\end{array}$ & $\begin{array}{c}\text { Costo CC } \\
\text { (\$) }\end{array}$ \\
\hline Ácido clorhídrico & 2500 & $\mathrm{ml}$ & 31,20 & 3,00 & $\mathrm{ml}$ & 0,04 \\
Ácido sulfúrico & 2500 & $\mathrm{ml}$ & 45,90 & 360,00 & $\mathrm{~m} \mathrm{l}$ & 6,61 \\
Permanganato de sodio & 500 & $\mathrm{~g}$ & 52,03 & 18,00 & $\mathrm{G}$ & 1,87 \\
Peróxido de hidrogeno & 1000 & $\mathrm{ml}$ & 7,00 & 6,00 & $\mathrm{ml}$ & 0,04 \\
Grafito sintético & 1000 & $\mathrm{~g}$ & 2,50 & 3,00 & $\mathrm{G}$ & 0,01 \\
Ácido fosfórico & 1000 & $\mathrm{ml}$ & 3,50 & 40,00 & $\mathrm{ml}$ & 0,14 \\
\hline \multicolumn{7}{c}{ Costo total para producir $\mathbf{0 , 6 6}$ g de OG sintético } \\
\hline
\end{tabular}

Tabla 4.

Costos asociados a unidades de mezcla base.

\begin{tabular}{lcccccc}
\hline \multicolumn{1}{c}{ Materiales } & $\begin{array}{c}\text { Cantidad } \\
\text { adquirida }(\mathbf{C A})\end{array}$ & $\begin{array}{c}\text { Costo CA } \\
\mathbf{( \$ )}\end{array}$ & $\begin{array}{c}\text { Cantidad } \\
\text { consumida (CC) }\end{array}$ & $\begin{array}{c}\text { Costo CC } \\
(\mathbf{\$})\end{array}$ \\
\hline cemento & 50 & $\mathrm{~kg}$ & 7,49 & 83,33 & $\mathrm{~g}$ & 0,012 \\
arena & 48 & $\mathrm{~kg}$ & 1,00 & 229,17 & $\mathrm{~g}$ & 0,005 \\
policarboxilato & 1000 & $\mathrm{~g}$ & 3,35 & & & 0,003 \\
\hline \multicolumn{7}{c}{ Costo total por probeta de $\mathbf{5 \times 5 \times 5 \mathbf { c m } ^ { \mathbf { 3 } }}$} \\
\hline
\end{tabular}

Tabla 5

Costos asociados a unidades de mezcla reforzada con G-O y rG-O.

\begin{tabular}{|c|c|c|c|c|c|c|}
\hline $\begin{array}{l}\text { Dosificación } \\
\text { de G-O } \\
\text { sintetizado \% } \\
\text { del peso del } \\
\text { cemento } \\
\end{array}$ & $\begin{array}{c}\text { Costo por } \\
5 \times 5 \times 5 \mathrm{~cm}^{3} \\
\text { de mortero } \\
\left(\mathrm{cm}^{3} / \$\right)\end{array}$ & $\begin{array}{c}\begin{array}{c}\text { Costo } \\
\text { de } \\
\text { mortero } \\
\left(\mathrm{m}^{3} / \mathbf{S}\right)\end{array}\end{array}$ & $\begin{array}{c}\text { Costo por } \\
\text { dosificación } \\
\text { de } G-O \text { por } \\
5 \times 5 \times 5 \mathrm{~cm}^{3} \\
\left(\mathrm{~cm}^{3} / \$\right)\end{array}$ & $\begin{array}{c}\text { Costo por } \\
\text { dosificación } \\
\text { de } G-O \\
\left(\mathbf{m}^{3} / \mathbf{\$}\right)\end{array}$ & $\begin{array}{c}\text { Costo de } \\
\text { mezcla } \\
\text { reforzada con } \\
\mathrm{G}-\mathrm{O},\left(\mathrm{m}^{\mathbf{3}} / \$\right)\end{array}$ & $\begin{array}{c}\text { Factor de } \\
\text { incremento de } \\
\text { costos entre: } \\
\text { mezcla reforzada y } \\
\text { mezcla base de } \\
\text { mortero }\end{array}$ \\
\hline $0,03 \%$ & 0,02 & 160,00 & 0,33 & 2607,72 & 2767,72 & 17 \\
\hline $0,04 \%$ & 0,02 & 160,00 & 0,43 & 3473,44 & 3633,44 & 23 \\
\hline $0,05 \%$ & 0,02 & 160,00 & 0,54 & 4339,16 & 4499,16 & 28 \\
\hline $0,06 \%$ & 0,02 & 160,00 & 0,65 & 5204,88 & 5364,88 & 34 \\
\hline $\begin{array}{c}\text { Dosificación } \\
\text { de rG-O } \\
\% \text { del peso } \\
\text { del cemento }\end{array}$ & $\begin{array}{c}\text { Costo por } \\
5 \times 5 \times 5 \mathrm{~cm}^{3} \\
\text { de mortero } \\
\left(\mathrm{cm}^{3} / \mathbb{S}\right)\end{array}$ & $\begin{array}{c}\begin{array}{c}\text { Costo } \\
\text { de } \\
\text { mortero } \\
\left(\mathrm{m}^{3} / \mathbb{S}\right)\end{array}\end{array}$ & $\begin{array}{c}\text { Costo por } \\
\text { dosificación } \\
\text { de rG-O por } \\
5 \times 5 \times 5 \mathrm{~cm}^{3} \\
\left(\mathrm{~cm}^{3} / \$\right)\end{array}$ & $\begin{array}{c}\text { Costo por } \\
\text { dosificación } \\
\text { de rG-O } \\
\left(\mathbf{m}^{\mathbf{3}} / \mathbf{\$}\right)\end{array}$ & $\begin{array}{c}\text { Costo de } \\
\text { mezcla } \\
\text { reforzada con } \\
\text { rG-O, }\left(\mathrm{m}^{\mathbf{3}} / \$\right)\end{array}$ & $\begin{array}{c}\text { Factor de } \\
\text { incremento de } \\
\text { costos entre: } \\
\text { mezcla reforzada y } \\
\text { mezcla base de } \\
\text { mortero }\end{array}$ \\
\hline $0,03 \%$ & 0,02 & 160,00 & 4,69 & 37544,00 & 37704,00 & 236 \\
\hline $0,04 \%$ & 0,02 & 160,00 & 6,25 & 50008,00 & 50168,00 & 314 \\
\hline $0,05 \%$ & 0,02 & 160,00 & 7,81 & 62472,00 & 62632,00 & 391 \\
\hline $0,06 \%$ & 0,02 & 160,00 & 9,37 & 74936,00 & 75096,00 & 469 \\
\hline
\end{tabular}

62 


\section{Conclusiones}

En esta investigación se planteó determinar el incremento de la resistencia mecánica a la compresión en cubos de mortero reforzados con óxido de grafeno, registrando los costos de producción del aditivo y mortero reforzado por unidad volumétrica ensayada. En la primera etapa se evaluó la posibilidad de extraer grafeno de muestras de esquistos de grafito procedentes del yacimiento ubicado en la provincia de Loja, y se determinó un alto porcentaje de impurezas (otros minerales) con bajo porcentaje de carbono en dicho caso no resulta factible su depuración desde puntos de vista técnico o económico. Posterioremente, utilizando grafito sintético para el proceso de producción de óxido de grafeno (G-O) mediante síntesis química y su comparación con el óxido de grafeno reducido ( $\mathrm{rG}-\mathrm{O}$ ), es posible validar el proceso de síntesis y realizar el análisis de costos.

El análisis comparativo entre los resultados de esta investigación y publicaciones precedentes ( $\mathrm{Lv}$ et al., 2013; Wang et al., 2015; Abrishami y Zahabi, 2016; Long et al., 2017) respecto al comportamiento de mezclas de mortero reforzado con óxido de grafeno a compresión, se realiza en función del comportamiento que presentan los valores de resistencia cuando se utiliza el refuerzo de óxido de grafeno entre los porcentajes 0,03 a 0,06 del peso del cemento presente en la mezcla para 14 días de curado. En este sentido los ensayos muestran una respuesta de mejora de la resistencia similar a los estudios previos. Adicionalmente dicho resultado valida como correcto, el trabajo de síntesis química realizado.

En el estudio del comportamiento mecánico bajo cargas de compresión aplicadas a cubos de mortero, reforzados con óxido de grafeno (obtenido por el método de síntesis química "Improved Synthesis of Graphene Oxide"), y muestras reforzadas con óxido de grafeno reducido, en ambos casos se incorporó policarboxilato $(0,5 \%$ de peso de cemento) para optimizar las propiedades de adhesión del óxido de grafeno y su dispersión en la matriz de cemento (Babak et al., 2014; Kjaernsmo et al., 2018). Teniendo en cuenta que no se utilizó la dispersión mediante ultrasonido (sonicación) para mejorar la solubilidad de óxido de grafeno en el agua lo que implícitamente mejora la adherencia entre el G-O y el cemento, se recomienda repetir el ensayo incoporando la sonicación para determinar el efecto en el comportamiento de la resistencia a compresión.

Para las muestras reforzadas con óxido de grafeno sintetizado con $0,06 \%$ de peso de cemento se incrementa la resistencia en $28,12 \%$, mientras que las muestras reforzadas $\mathrm{rG}-\mathrm{O}$ con igual contenido en peso de cemento incrementa un $42.87 \%$, por tanto, obtuvo una resistencia más alta.

En relación al costo por $\mathrm{m}^{3}$ de mortero reforzado con G-O y rG-O, los costos con G-O son inferiores a los costos con rG-O realizando el comparativo solo respecto al procesos de síntesis más la mezcla base (Tablas 4 y 5). 
Se evaluaron los costos implicados en la producción de óxido de grafeno a partir de esquistos grafitícos del cerro Villonaco obteniendo un valor aproximado de 7655,81 U\$, mientras que realizar la experimentación con óxido de grafeno reducido tuvo un costo aproximado de 2656,68 U\$, sin incluir los costos de importación de las herramientas y máquinas.

\section{Agradecimientos}

Los autores del presente trabajo expresan su gratitud a la Escuela Superior Politécnica del Litoral y a en especial a las Facultades FICT y FCNM, Ing. Geólogo Nelson Guamán por asesoría en la extracción de muestras. Ing. Washington Pincay encargado del laboratorio del laboratorio de Mineralurgia de la Facultad de Ingeniería en Ciencias de la Tierra (FICT) de la ESPOL, Ing. Tyrone Alcivar por el soporte en el proceso experimental de síntesis química en laboratorio de hidrocarburos del FCNM y a la PhD. Carmen Terreros en el área de tecnología del hormigón.

\section{Referencias}

Abrishami, M. E., y Zahabi, V. (2016). Reinforcing graphene oxide/cement composite with NH2 functionalizing group. Bulletin of Materials Science, 39 (4), 1073-1078.

Alarcon, G. L. (1998). Analisis de mezclas para morteros de enlucidos utilizando arena cuarcifera de la formacion Hollin, Tesis de Titulación en Ingienieria Civil. Escuela Superior Politécnica del Litoral. Ecuador. Recuperado de: http://www.dspace.espol.edu.ec/xmlui/ha ndle/123456789/3380
Amor G.M. (2017). Grafeno: biografía de un material. Bachelor Thesis Universidad Nacional de Educación a Distancia, Facultad de Filosofía: Historia de la Ciencia. España. Recuperado de: http://e-spacio.uned.es/fez/view/bibliune d:grado-Filosofia-Filosofia-Mamor

Sánchez de Guzmán, D. (2011). Tecnología del Concreto Tomo 2. Manejo y colocación en obra ( $3^{\text {a }}$ ed.) Editorial:Asociación Colombiana de Productores de Concreto, Asocreto. Colombia.

ASTM International. (2008). Standard Test Method for Compressive Strength of Hydraulic Cement Mortars (Using 2-in. or [50-mm] Cube Specimens). Recuperado de: https://www.astm.org/DATABASE.CAR T/HISTORICAL/C109C109M-08.htm

Babak, F., Abolfazl, H., Alimorad, R., Parviz, G., Hassani, A., y Rashidi, A. (2014). Preparation and Mechanical Properties of Graphene Oxide: Cement Nanocomposites. Hindawi Publishing Corporation The Scientific World Journal. 2-11

González B., D. R. (2016). Cartografía Litológico -Estructural y Análisis Petrográfico del Intrusivo del Cerro Villonaco, Tesis Titulación de Ingeniero en Geología y Minas. Universidad Técnica Particular de Loja. Ecuador. Recuperado de: http://dspace.utpl.edu.ec/handle/1234567 $89 / 13534$

Carrasco, F. (2013). Agua para morteros y hormigones. En: Tecnología del Hormigon (Eds.). 1-19. Argentina: Universidad Tecnológica Nacional

Coordinación general de minería de México. (2014). Perfil de Mercado del Grafito. Sub-secretaría de Minería. México. Recuperado de: https://www.gob.mx/cms/uploads/attachm ent/file/287801/Perfil_Grafito_2017.pdf

Geim, A. K. \& Novoselov K.S. (2007). The rise of 
graphene. Manchester Centre of Mesoscience and Nanotechnology. England: Nature Publishing Group.

Chuah, S., Pan, Z., Sanjayan, J. G., Wang, C. M., y Duan, W. H. (2014). Nano reinforced cement and concrete composites and new perspective from graphene oxide. Construction and Building Materials, 73, 113-124.

Dominguez, B. J., y Adrados, G. L. (1997). Morteros y aditivos. Fabricacion Investigacion y Aplicaciones del Cemento y del Hormigon, 68(774), 1040-1056.

Fallas, G. G., Madrigal, C. H., García, M. P., Valenciano, I. R., Vega, L. D., y Guzmán, G. S. (2011). Efecto de la variación agua/cemento en el concreto. Revista Tecnología en Marcha, 25(2), 80-86.

Goicoechea, M. (2017). Propiedades mecánicas de morteros de cemento con adiciones de fibras de carbono, nanotubos de carbono y grafeno. Mechanical properties of cement mortars with additions of carbon fibres, carbon nanotubes and graphene. Anales de Edificación, 3(3), 12-19.

González, J. (Marzo de 2016). Estudio del mortero de pega usado en el cantón cuenca.propuesta de mejora, utilizando adiciones de cal. Tesis de Maestría en Construcciones. Universidad de Cuenca. Ecuador. Recuperado de:

http://dspace.ucuenca.edu.ec/handle/123 $456789 / 23664$

NTE-INEM 2518. (2010). Norma Técnica Ecuatoriana: Morteros para Unidades de Mampostería ( $1^{\mathrm{a}}$ ed.). Instituto Ecuatoriano de Normalización Ecuador.

Kehr, M. (2008). Estudio comparativo de la razón agua/cemento de la nch 170 y de la tabla 22 razón agua/cemento de vialidad. Tesis de titulación en Constructor Civil. Universidad Austral de Chile. Chile. Recuperado de: http://cybertesis.uach.cl/tesis/uach/2008/ bmfcik.26e/doc/bmfcik.26e.pdf

Kjaernsmo, H., Kakay, S., Fossa, K. T., y Gronli, J. (2018). The Effect of Graphene Oxide on Cement Mortar. In IOP Conference Series: Materials Science and Engineering (Vol. 362, No. 1, p. 012012). IOP Publishing.

Long, W. J., Wei, J. J., Ma, H., y Xing, F. (2017). Dynamic mechanical properties and microstructure of graphene oxide nanosheets reinforced cement composites. Nanomaterials, 7(12), 407.

Lv, S., Ma, Y., Qiu, C., Sun, T., Liu, J., y Zhou, Q. (2013). Effect of graphene oxide nanosheets of microstructure and mechanical properties of cement composites. Construction and Building Materials, 49, 121-127

Murray, R. (2013). Graphene 101 an inventor's, guide to making graphene. Estados Unidos: Smashwords Edition

Ramos, G. (2017). Efecto de la química superficial del óxido de grafeno en el desarrollo de aplicaciones. Tesis de Doctorado. Universidad de Alicante, España. Recuperado de: http://hdl.handle.net/10045/71402

Romani A. (2015). Graphene Oxide as a cement reinforcing additive. Master Thesis of Science in Materials Engineering and Nanotechnology, Politecnico di Milano, School of Industrial and Information Engineering, Italia. Recuperado de: http://hdl.handle.net/10589/111981

Rodríguez, M. Ó. (2008). Morteros Guía General. España: Raro Producciones.

Orozco, L. Y. (2012). Estudio del efecto del tipo y concentración de espumante en la selectividad del proceso de flotación a escala laboratorio. Tesis de titulación en Ingeniería Civil Quimica. Universidad de 
Chile. Chile. Recuperado de: http://repositorio.uchile.cl/handle/2250/1 11986

Totarolo, G. M., y Prisant, G. M. (2012). Grafeno: ¿La siguiente revolución tecnológica?. Revista ¿Cómo ves?, 164, 22-25.

Trujillo, J. J. (2014). Pastas, morteros, adhesivos y hormigones. España: IC Editorial.

Marcano D. C, Kosynkin D. V., Berlin J. M., Sinitskii A., Sun Z., Slesarev A., Alemany L. B., Lu W. y Tour J. M. (2010). Improved Synthesis of Graphene Oxide. ACSNANO 4(8) 4806.4814.

Uribe, R. (2015). Investigaciones de materias primas minerales no metálicas en el Ecuador. Revista Politécnica, 36(3), 34-44.

Vargas, D. (2016). Síntesis de óxido de grafeno reducido y aminado químicamente y su influencia en las propiedades eléctricas y mecánicas de nanocompósitos a base de caucho natural. Tesis de Licenciatura en Química. Universidad de Chile, Chile.

Wang, Q., Wang, J., Lu, C.-x., Liu, B.-w., Zhang, K., y Li, C.-z. (2015). Influence of graphene oxide additions on the microstructure and mechanical strength of cement. New Carbon Metarials, 30(4), 349-356 